\title{
Do biopoder à psicopolítica
}

\section{Débora Aymoré1}

1 Bacharel em Direito (UFPA, 2004), Especialista em Filosofia e Epistemologia das Ciências Humanas (UFPA, 2007), Mestre em Filosofia (USP, 2010), Doutora em Filosofia (USP, 2015) com estágio de pesquisa no exterior com bolsa CAPES (University of Miami, FL, 2013-2014), Pósdoutorado (USP, 2017 - 2018). Professora Substituta do curso de Filosofia da Universidade Federal do Paraná (UFPR).

E-mail: deboraaymore@yahoo.com.br Orcid http://orcid.org/0000-0003-1384-6681

RESUMO: Nossa condição humana contemporânea está inter-relacionada com o avanço do domínio das aplicações tecnológicas para vários aspectos da vida biológica, existencial e política, levantando uma postura reflexiva diante das tecnologias de informação. Se é verdade que o projeto baconiano estimula, a partir do século XVI, o controle sobre a natureza, a partir dos séculos XVII e XVIII, a Europa testemunhou o nascimento de duas formas de poder moderno: o poder disciplinar e o biopoder. Assim, a estratégia adotada para o exercício do controle sobre os seres humanos assume proporções individuais (corpos individuais) e sociais (espécie) como também as mentes. Na medida em que a imaginação é fonte de exercício de liberdade, mesmo que momentânea entre as subjetividades disciplinadas, as tecnologias de informação representam a capacidade de interferir no nível pré-cognitivo, misturando as fronteiras que representam a modernidade: o corpo e a mente, a razão e a paixão, a liberdade e a responsabilidade. Testemunhamos, especialmente a partir do século XX em diante o surgimento do controle tal como exercido pela psicopolítica.

Palavras-chave: biopoder, psicopolítica, subjetividade.

ABSTRACT: Our contemporary human condition is inter-related to the advancement of technological application's dominations throughout various aspects of biological, existential, and political life, raising a reflexive posture applied to information technology. If it is true that the Baconian project stimulates, since 16th Century, the control of nature, from 17th and 18th Centuries, Europe testifies the emergence of two modern forms of power: disciplinary power and biopower. Therefore, the strategy adopted to exercise control over humans assumes both individual (human bodies) and social proportions (human species), as well as human minds. Considering imagination as a possible means of exercising freedom, although momentarily, among disciplined subjectivities, technologies of information represents the ability to interfere in a subcognitive level, mixing boundaries that overruns Modernity, such as: body and mind, reason and passion, freedom and responsibility. We testify, mainly from 20th Century and on, the emergency of control as exercised by Psychopolitics.

Key-words: Biopower, Psychopolitics, Subjectivity.

\section{Introdução}

Há um sentimento de liberdade envolvido na passagem de um modo de vida para o outro (cf. HAN, 2018, p. 9). Pensa-se, por exemplo, que o solteiro quando passa para a condição de casado, ou mesmo desta condição para a de separado; nas duas situações sente-se a liberdade, até que esta última condição seja também sentida como uma espécie de coerção. Estaria a contemporaneidade fadada à liberdade episódica? Àquela que depende diretamente da mudança de um estado para o outro e não da permanência de uma condição escolhida autonomamente pelo sujeito? 
Byung-Chul Han considera que, embora nossa condição seja a de sujeitos submissos, somos sempre projetos livres. E, no entanto, nesta consideração de sujeito como projeto, livre das coerções externas e da restrição imposta pelo outro, se lida contemporaneamente com a sujeição interna, ou melhor, internalizada. Pois ela resulta das "obrigações de desempenho e de otimização" (HAN, 2018, p. 9). Trata-se de reconhecer a mudança em nossa concepção de sujeito para o sujeito do desempenho, um autoempreendedor de si mesmo.

Há que se notar, no entanto, que ainda que passemos a nos autocompreender como sujeitos de desempenho, permanecem três restrições que nos são inerentes: a primeira, a nossa mortalidade, a segunda a corporeidade e a terceira nossos meios tecnológicos utilizados, entre outros objetivos, para nossa interação social.

É por isso que, nesta condição de projeto, o sujeito pensado não apenas em abstrato, mas em concreto, pois não se deixa de ter um corpo vivo, que está restringido em seus projetos de si por uma situação fundamental: o tempo, que se revela para o ser humano como tempo de vida, associado à consciência em relação ao fim de sua existência no mundo. Deste modo, considerando que a liberdade é a "antagonista da coerção" (HAN, 2018, p. 10), nossos projetos de vida sofrem a primeira restrição: a nossa mortalidade.

Segue-se a esta a segunda restrição, talvez tão invisível quanto a primeira: nossa corporeidade. Caso o antropólogo David Le Breton esteja correto em sua análise, a partir da Modernidade esquecemos o corpo (cf. Le Breton, 2013). Somando-se a esta caracterização à de Han, podemos afirmar que a ênfase no projeto, no autoempreendimento de nós mesmos, faz com que, pelo menos por alguns momentos, esqueçamos o corpo. Até que ele nos forneça sinais das restrições que nos impõe: o cansaço, a fome, a doença. Todas estas situações são indícios que nos relembram que o corpo é, ele próprio, uma condição de possibilidade para a realização dos projetos que o sujeito põe para si, mesmo quando se supõe numa aparente relação de "autoprodução ilimitada" (HAN, 2018, p. 15).

Finalmente, a terceira restrição, que permanece invisível e, tal como as demais, deve ser explicitada uma vez que afeta também a autocompreensão quanto à mortalidade e quanto à corporeidade. Penso especialmente nas tecnologias, cujos usos cada vez mais se naturalizam, entremeando-se nos níveis micro e macro das relações sociais. Seguindo, por vezes, a lógica da cura ou o melhoramento, as biotecnologias se dedicam ao corpo, seja em sua infraestrutura (moléculas de DNA), seja em relação à superestrutura (corpo político). Tornando o sujeito-projeto ou sujeito do desempenho capaz, por um lado, de realizar escolhas mesmo naquilo que se considerava mais próximo da natureza, ou seja, no corpo vivo; e, por outro lado, este mesmo corpo torna-se cada vez mais refém das "tiranias e das delícias do upgrade" (SIBILIA, 2015, p. 14).

Com as biotecnologias tornamos nossas escolhas cada vez mais complexas, chegando mesmo à possibilidade de direção artificial da seleção da espécie humana, projetados como esperanças a partir dos usos do diagnóstico genético pré-implantação ou mesmo devido à pesquisa realizada por intermédio do Projeto Genoma Humano. No entanto, se considerarmos que as escolhas individuais estão condicionadas por fatores internos (valores) e externos (situação), é possível questionar em que ponto a superutilização da estratégia do controle da natureza pode se desdobrar em controle sobre os seres humanos. Questionando se, devido ao uso excessivo das tecnologias de informação, não estamos manufaturando, ou melhor, programando mentes.

Nos dois casos, tanto das biotecnologias, quanto da tecnologia da informação, nossa angústia contemporânea se revelaria, então, como sensação de constante insatisfação, de inadequação, pois cada novo projeto apresenta como prelúdio o reconhecimento de que a mudança, o fluxo, é mais importante que a 
permanência e a estabilidade. No entanto, na medida em que o ser humano é não apenas projeto, mas um agente capaz de significar as suas ações, sem a estabilidade fornecida pela autocompreensão de si mesmo, nada nos resta senão um constante sentido de insatisfação. Tornado do sujeito-projeto um angustiado diante das possibilidades de realização de si mesmo ou ainda um depressivo (cf. HAN, 2018, p. 16).

Neste sentido geral, a tecnociência comercialmente orientada, e mais especificamente as biotecnologias e tecnologias de informação, podem exercer uma dupla função: inicialmente libertadora da mente de sua condição corpórea (por exemplo, por meio da realidade virtual ou com o uso do avatar que mais nos convém), torna-se a seguir constrangedora, por nossa imaginação clamar igualmente por significados consistentes, que perdurem ao longo do tempo. Porém, tal consistência parece depender na contemporaneidade, primeiramente, de uma reapropriação do passado da tecnociência, o que pode suscitar busca de compreensão do projeto baconiano (de onde viemos?). E, em segundo lugar, para a tomada de posicionamento diante o futuro que queremos, individual e coletivamente (para onde vamos?). Ou seja, uma tentativa de reconhecer a agência como central à experiência humana.

Assim, em um mundo que se fluidifica, se imaterializa ou se expande por intermédio da realidade virtual e de um sujeito que se modifica sempre e mais intensamente com ênfase em um projeto de si que nunca é satisfeito, mesmo que não saibamos muito bem para onde estamos indo, resgatar a função do corpo na nossa existência pode ser compreendido como forma de resistência.

No que segue, seguiremos nossa trajetória a partir da concepção de Biopolítica, tal com exposta especialmente por Michel Foucault, e, a seguir, consideraremos com mais ênfase a formação da Psicopolítica, tal como desenvolvida por Byung-Chul Han, considerando as tecnologias de controle disponíveis em cada caso. Considerando estes dois diagnósticos histórico-filosóficos, refletiremos sobre o significado que o sujeito do desempenho atribui à existência, que pode resultar em sentimentos ambíguos quanto à liberdade, abstrata e concretamente dada nas ações e práticas sociais.

\section{Biopoder ou o controle sobre o corpo}

Michel Foucault (1926 - 1984) se inspira na imagem do pan-óptico de Jeremy Bentham (1748 1832) em sua analítica do poder, pois este modelo arquitetônico guarda em si uma síntese das formas modernas segundo as quais o poder é exercido: primeiramente na forma de poder disciplinar e, posteriormente, na forma de biopolítica. Apesar do distanciamento temporal entre os dois autores, Foucault considerará que é a partir do século XIX que se consubstancia a estratégia biopolítica, vinculada ao desenvolvimento do capitalismo.

A obra O Panóptico de Bentham é composta de 21 cartas, escritas ao longo do ano de 1787, e, como ele mesmo nos informa na Carta I, trata-se de apresentar uma arquitetura que pode ser empregada para diferentes propósitos: “[...] o de punir o incorrigivel, encerrar o insano, reformar o viciado, confinar o suspeito, empregar o desocupado, manter o desassistido, curar o doente, instruir os que estejam dispostos [...]" (BENTHAM, 2019, p. 19). Assim, esta arquitetura pensada a partir do princípio de economia é potencialmente aplicável às penitenciárias, às manufaturas, aos hospícios, aos hospitais, às escolas.

Então, o que se tem em vista é a possibilidade de manter a inspeção ou a vigilância sobre os corpos a cada momento no tempo ou, pelo menos, o vigiado deve "[...] pensar que está nessa condição" (BENTHAM, 2019, p. 20). Na Carta II há uma descrição detalhada deste plano de inspeção: 
O edifício é circular.

Os apartamentos dos prisioneiros ocupam a circunferência. Você pode chamá-los, se quiser, de celas.

Essas celas são separadas entre si e os prisioneiros, dessa forma, impedidos de qualquer comunicação entre eles, por partiçoes, na forma de raios que saem da circunferência em direção ao centro, estendendo-se por tantos pés quantos forem necessários para se obter uma cela maior.

O apartamento do inspetor ocupa o centro; você pode chamá-lo, se quiser, de alojamento do inspetor.

Será conveniente, na maioria dos casos, se não em todos, ter-se uma área ou um espaço vazio em toda volta, entre esse centro e essa circunferência. Você pode chamá-lo, se quiser, de área intermediária ou anular (BENTHAM, 2019, p. 20 - 21).

A descrição continua e, no entanto, nota-se desde logo que um elemento importante para o panóptico de Bentham é manter o isolamento, a incomunicabilidade entre os prisioneiros, entre àqueles que são vigiados. Separados os corpos, não apenas do entorno social mais amplo, mas entre si, os prisioneiros dispõem de tempo suficiente para uma gradual subjetivação da vigilância. Cerceados de sua liberdade de ir e vir, e impedidos como estão de estabelecer relações de significado com os demais, provoca-se pelo menos dois efeitos: o da onipresença do poder de vigilância e o da impossibilidade de resistência dos indivíduos.

Para Foucault outro elemento importante da analítica do poder é a sexualidade que fora isolada desde o século XVII e intensificando-se no século XIX. O corpo é vigiado por meio da repressão, dando forma ao puritanismo moderno. Ademais a "[...] repressão funciona, decerto, como condenação ao desaparecimento, mas também como injunção ao silêncio, afirmação da inexistência e, consequentemente, constatação de que, em tudo isso, não há nada para dizer, nem para ver, nem para saber" (FOUCAULT, 2014, p. 8).

Constatando a relação entre o poder, o saber e a sexualidade, em sua injunção histórica com o desenvolvimento do capitalismo, colocando-nos a questão nesta "[...] época em que se explora sistematicamente a força de trabalho, poder-se-ia tolerar que ela fosse dissipar-se nos prazeres, salvo naqueles reduzidos ao mínimo, que lhe permitem reproduzir-se?” (FOUCAULT, 2014, p. 10).

Deste modo, o biopoder surge como estratégia de controle individual e social, visando à produção de corpos e mentes dóceis e aptas ao trabalho, eficazmente aplicados e sem desperdícios. E, assim, "[...] a junção entre o ‘corpo' e a ‘população', o sexo tornou-se o alvo central de um poder que se organiza em torno da gestão da vida, mais do que da ameaça de morte” (FOUCAULT, 2014, p. 159). A ameaça de morte do poder soberano é considerada como forma de exercício de poder pré-moderna, pois a partir da modernidade cabe canalizar as energias vitais para a produção, evitando a dissipação.

Cabe notar, segundo Foucault, que os teóricos clássicos colocam o direito de vida e morte como forma de poder atenuada, pois ele "[...] já não é um privilégio absoluto: é condicionado à defesa do soberano e à sua sobrevivência enquanto tal" (FOUCAULT, 2014, p. 145). E, assim, enquanto o poder soberano está vinculado à ordem jurídica da soberania que, como vimos, apresenta limites especialmente quando decisão sobre a vida e a morte, o biopoder passa a se vincular ao biológico, aproximando-se cada vez mais da população (cf. FOUCAULT, 2014, p. 148). A partir do século XVI duas formas de poder se projetam na gestão da vida:

Um dos polos, o primeiro a ser formado, ao que parece, centrou-se no corpo como máquina: no seu adestramento, na ampliação de suas aptidões, na extorsão de suas forças, no crescimento paralelo de sua utilidade e docilidade, na sua integração em sistemas de controle eficazes e econômicos - tudo isso assegurando por procedimentos de poder que caracterizam as disciplinas: anátomo-política do corpo bumano. O segundo, que se formou um pouco mais tarde, por volta da metade do século XVIII, centrou-se no corpo-espécie, no corpo transpassado pela mecânica do ser vivo e como suporte dos processos bioló- 
gicos: a proliferação, os nascimentos e a mortalidade, o nível de saúde, a duração da vida, a longevidade, com todas as condições que podem fazê-los variar; tais processos são assumidos mediante toda uma série de intervenções e controles reguladores: uma biopolítica da populaşão (FOUCAULT, 2014, p. 150).

As duas facetas do biopoder se instauram, por um lado, dedicando-se ao corpo humano, sua disciplina e sua integração ao sistema econômico. E, por outro lado, a partir do século XVIII a atenção se volta à espécie, convertendo-se em gestão das populações, por meio da biopolítica. De acordo com esta chave de leitura, a gestão da vida não se baseia necessariamente em interesses humanitários. Subjaz ao maquinário da disciplina e do controle dos corpos e das mentes, a necessidade de atendimento da produção, pela necessidade de formar corpos disponíveis para o trabalho.

Se isto é verdade e, uma vez que, para Bresser-Pereira, o capitalismo inicia no norte da Itália no século XIII e, a partir do século XIV, completando o ciclo de revolução capitalista com a Revolução Industrial da Inglaterra no século XVIII (cf. BRESSER-PEREIRA, 2011; 2018), torna-se compreensível a afirmação de Comparato, segundo a qual: o "[...] poder econômico capitalista está intimamente ligado à capacidade de permanente acumulação e centralização do capital” (COMPARATO, 2011, p. 266).

Assim, a análise de Foucault sobre a emergência do biopoder estaria centrada especialmente na fase de desenvolvimento do capitalismo industrial. Desta maneira, modificadas as formas sociais de produção e de acumulação do capital, abre-se a expectativa de novas formas de autocompreensão do sujeito, em paralelo com a emergência de novos instrumentos de controle.

\section{Psicopolítica ou o controle sobre a mente}

Nossas formas de vigilância se aprimoraram, graças ao desenvolvimento da tecnologia de informação. A internet, criada em 1969, denominava-se inicialmente Aparnet, conectando laboratórios de pesquisa. Apenas em 1987 seu uso comercial foi liberado, expandindo ainda mais o uso a partir da criação da World Wide Web, permitindo a disponibilidade de informações para os usuários de internet. Estima-se em dados de 2011, que o número de usuários ultrapassou o número de 250 milhões (cf. SILVA, 2001). Assim, a tecnologia que surge nos Estados Unidos durante a Guerra Fria em 1960, passa pelo momento abertura para pesquisa civil a partir de 1970, bem como por melhorias na criação de protocolos (HTTP e HTTPS) desde 1980. Trata-se, assim, devido ao número de usuários e a quantidade de informações colocadas em circulação, de uma das aplicações tecnológicas motivadoras do questionamento de se vivenciamos no pós-panótico.

Ao menos, esta é a interpretação de Han que, mesmo partilhando as bases da analítica do poder de Foucault sustentando a imbricação entre saber e poder, considera que a euforia inicial de que a rede nos traria um exercício ampliado da liberdade, mostrou-se uma ilusão. Isto porque, para ele:

A liberdade e a comunicação ilimitadas se transformaram em monitoramento e controle total. Cada vez mais as mídias sociais se assemelham a pan-ópticos digitais que observam e exploram impiedosamente o social. Mal nos livramos do pan-óptico disciplinar e já encontramos um novo e ainda mais eficiente (HAN, 2018, p. 19).

Além desta constatação já por si mesma espantosa, Han explicita o que seria a nossa relação de reforço em relação à vigilância, uma vez que nos integramos às engrenagens de comunicação e de interação constantes. E, assim, segundo Han: "Os internos do pan-óptico digital, por sua vez, comunicam-se intensivamente e expõem-se por vontade própria” (HAN, 2018, p. 19). Algo que, segundo Ana Cristina Garcia 
Dias e Marco Antônio Pereira Teixeira afeta, inclusive, o modo como nos relacionamos com outras pessoas, uma vez que a

Internet é um ambiente onde a auto-revelação tem um papel central nas interações que são estabelecidas. É através das habilidades que o indivíduo tem para se auto-revelar e compartilhar pontos de vista pessoais na rede que uma relação pode ser construída, mantida ou transformada (DIAS e TEIXEIRA, 2008, p. 24)

Assim, para além das revelações interpessoais, a ênfase no virtual descaracteriza pelo menos em parte o modelo do pan-óptico de Betham, embora seja também um reforço da vigilância. Se nos consideramos mais livres para realizamos nossas interações sociais supondo, inclusive, a independência em relação às coerções externas e à restrição imposta pelo outro, supomo-nos livres das três restrições materialmente dadas, e que funcionam como limitadoras da liberdade (mortalidade, corporeidade e tecnologias). Aparentando até, em certa medida, uma confusão entre o estado onírico das experiências subjetivas (pensamentos, emoções), geralmente percebidas individualmente, com a realidade própria do estado de vigília, vivenciada coletivamente, e, quem sabe, rejeitando a compreensão de produção e de trabalho concretamente dados, que considerávamos inerentes à experiência humana no mundo.

A psicopolítica, enquanto gestora mais de mentes que de corpos vivos, ocupa-se, principalmente, com o fluxo constante de informações, segundo a tirania da informação. No entanto, até mesmo a subjetividade pode ser vista como uma barreira para comunicação, pois sem a revelação de si não há informação a ser colocada em movimento e disponibilizada. Deste modo, a subjetividade precisa ser transparente, precisa ser colocada de dentro para fora, exposta de forma minuciosa, pois o mistério, o silêncio e o segredo são barreiras limitadoras da transparência da informação:

O segredo, o estranhamento ou a alteridade representam barreiras à comunicação ilimitada [entendida agora como uma positividade, caracterizada como crescimento]. [...] As pessoas também são 'desinteriorizadas', porque a interioridade atrapalha e retarda a comunicação. Contudo, a desinteriorização da pessoa não acontece de forma violenta, mas sim com a exposição voluntária de si mesmo (HAN, 2018, p. 20).

A liberdade, neste caso compreendida como a possibilidade de superexposição da subjetividade, está em conformidade com o desiderato da comunicação contante. Mas, não apenas isso. A captação das informações e o processamento dos rastros de nossas experiências virtuais podem ser escrupulosamente utilizados para manter nossos desejos, por um lado, ativos e, por outro, insatisfeitos, quando restritos aos interesses de consumo. Restando-nos, talvez, uma experiência de subjetividade reduzida, pois o interesse no fluxo constante de informações estaria voltado à manutenção do capital e do mercado. E, deste modo:

Os big data são um instrumento psicopolítico muito eficiente, que permite alcançar um conhecimento abrangente sobre as dinâmicas da comunicação social. Trata-se de um conhecimento de dominação que permite intervir na psique e que pode influenciá-la em um nível pré-reflexivo (HAN, 2018, p. 23).

Note-se, portanto, que a perda da privacidade dos dados é apenas um aspecto da vigilância contemporânea. Se concordarmos com Han, estamos perdendo até mesmo o sentido de interioridade, superexpondo nossas vidas subjetivas em troca do reconhecimento volátil e incessantemente fluido que a rede nos proporciona. Buscando o cultivo das relações sociais, perdemo-nos, por vezes, no hedonismo do au- 
tocultivo do que expomos ser nossa subjetividade: "No final, a abertura serve à comunicação sem limites, que é oposta ao fechamento, à reserva e à interioridade” (HAN, 2018, p. 20).

Assim, o sujeito do desempenho se autorrepresenta como livre em relação às limitações de tempo de vida (mortalidade), da sua biologia (corporeidade) e das tecnologias, dado que elas também desaparecem no fluxo das informações. Mas ele seria, segundo Han, um prisioneiro das próprias condições de estruturais de vivência da subjetividade contemporâneas. E se, além disso, alcançamos o nível de vigilância e de intervenção no nível pré-reflexivo, então vivenciamos a tirania da comunicação, do fluxo das informações. Na medida em que a

[...] abertura do futuro é constitutiva da liberdade de ação. Contudo, os big data tornam possíveis prognósticos sobre o comportamento humano. Dessa maneira, o futuro se torna previsível e controlável. A psicopolítica digital transforma a negatividade da decisão livre na positividade de um estado de coisas. A própria pessoa se positiviza em coisa, que é quantificável, mensurável e controlável. Nenhuma coisa porém é livre: todavia, é mais transparente do que uma pessoa. Os big data anunciam o fim da pessoa e do livre arbítrio (HAN, 2018, p. 23).

Deste modo, é possível que o controle sobre a mente não seja mais do que a sua manutenção em um estado de confusão, considerando que (1) as nossas experiências virtuais são continuamente interrompidas pela realidade, que (2) a comunicação com outros sujeitos que anseiam, entre outras coisas, a fuga em relação ao individualismo exacerbado e que (3) os interesses que dirigem a este estado de confusão seriam os do capital e mercado, fazendo com que até mesmo a liberdade, ou seja, nossa possibilidade de abertura para projetos futuros encontre-se comprometida, porque limitada ao exercício de uma perspectiva de valor. A rede virtual, que inicialmente configurava a promessa de expansão da subjetividade, mantém-na cativa.

\section{0 sujeito do desempenho é um projeto inacabado?}

$\mathrm{Na}$ medida em que a psicopolítica enfatiza, pelo uso das redes de comunicação à distância, o exercício da vigilância e do controle sobre as mentes, cabe-nos perguntar o que resta, então, do corpo e da liberdade?

Antes, no entanto, cabe relembrar que, segundo Han, estamos submetidos à relação com o capital que, na contemporaneidade, se volatizou. Enquanto a analítica do poder de Foucault se apresenta com o enfoque no desenvolvimento do capitalismo industrial, encontramo-nos diante de novas condições econômicas e de produção altamente eficientes na vigilância e na formação da subjetividade. E, assim, de acordo com Han:

O neoliberalismo é um sistema muito eficiente - diria até inteligente - na exploração da liberdade: tudo aquilo que pertence às práticas e às formas de expressão da liberdade (como a emoção, o jogo e a comunicação) é explorado. Explorar alguém contra a sua própria vontade não é eficiente, na medida em que torna o rendimento muito baixo. É a exploração da liberdade que produz o maior lucro (HAN, 2018, p. 11 - 12).

É possível afirmar que, a partir da exploração da liberdade e da superexposição da subjetividade, a economia neoliberal encontrou meios de maximizar lucros, enquanto os sujeitos de desempenho competem entre si. Deste modo, o "capital se multiplica enquanto competimos livremente uns com os outros" 
(HAN, 2018, p. 13). Tal competição não se restringiria apenas ao ambiente do trabalho, pois na busca de cada sujeito pelo reconhecimento social, o indivíduo pode projetar no outro um limite para a sua autorrealização e, assim, competimos para descobrir quem é o mais atraente, o mais feliz, o mais inteligente, o mais rico, o mais saudável, enquanto o mercado analisa as informações que obtém a partir da rede para nos oferecer a mercadoria mais apropriada.

Ao invés da liberdade, adquirimos uma nova forma de coerção. A invisibilidade do pan-óptico de Bentham poderia ser reconhecida como o resultado da interiorização de seus mecanismos. Pois, ao expormos nossa subjetividade supondo-nos livres, enquando, segundo Han: "O sujeito do desempenho, que se julga livre, é na realidade um servo: é um servo absoluto, na medida em que, sem um senhor, explora voluntariamente a si mesmo. Nenhum senhor o obriga a trabalhar" (HAN, 2018, p. 10).

O individualismo exacerbado, que se volta especialmente para o projeto de si, dificulta a possibilidade de compreensão coletiva do processo macro a que estamos submetidos, que visa realizar o que Jürgen Habermas julga ser o necessário esclarecimento da esfera pública diante de novas tecnologias, pois, para ele, mesmo

[...] os projetos individuais de vida não se formam independentemente dos contextos partilhados intersubjetivamente. No entanto, dentro de uma sociedade complexa, uma cultura só consegue se afirmar perante as outras convencendo suas novas gerações, que também podem dizer 'não', das vantagens de sua semântica que viabiliza o mundo e de sua força orientada para a ação (HABERMAS, 2004, p. 5).

Deste modo, se é verdade que "[...] cada um é um trabalhador que explora a si mesmo para a sua própria empresa. Cada um é senhor e servo em uma única pessoa. A luta de classes também se transforma em uma luta interior consigo mesmo" (HAN, 2018, p. 14), devemos reconhecer a interação recíproca entre os sujeitos (indivíduos, nível micro) e a sociedade (coletividade, nível macro). O sujeito do desempenho procura compartilhar nas interações sociais (reais ou virtuais) o que seria característico da sua subjetividade. Porém, exteriorizando-a, pode vir a sofrer críticas ou pedidos esclarecimento em relação à perspectiva de valor implicada em suas escolhas, na medida em que escolhas relativas aos projetos de vida estão relacionadas aos valores que, segundo Hugh Lacey, estamos dispostos a defender consistentemente (LACEY, 2008, p. 54). E é por isso que Habermas considera que mesmo a formação de nossa subjetividade individual é um empreendimento também coletivo. Pois, para ele:

O indivíduo arrepende-se dos aspectos condenáveis de sua vida pregressa e decide continuar agindo de modo em que ele consegue se reconhecer novamente sem se envergonhar. Sendo assim, ele articula a autocompreensão da pessoa que ele gostaria que os outros conhecessem e reconhecessem nele (HABERMAS, 2004, p. 10).

Se consideramos, tal como Habermas e Han, que contemporaneamente estamos diante de tecnologias capazes de alterar aspectos relativos à nossa autocompreensão moderna do sujeito e da subjetividade, quer do ponto de vista biológico voltado para a reprodução humana (por intermédio da biotecnologia), quer a partir do ponto de vista da mente (por intermédio das tecnologias de informação), tais tecnologias representariam, por um lado, o arauto da ampliação da liberdade, opondo natureza à cultura; mas, por outro lado, elas nos desorientam quanto à autocompreensão individual e coletiva que herdamos da modernidade, dificultando a realização de assentimento autônomo às novas aplicações tecnológicas.

Mesmo em relação aos valores, que seriam exercitados e, por vezes, defendidos em nossas práticas 
sociais (sejam elas reais ou virtuais), porque representativas da subjetividade que nos conforma, segundo Lacey

Os valores, para muitos, são profundamente pessoais, até mesmo privados; são parte da autodefinição de uma pessoa, de quem ela é; [...] Uma pessoa pode clarificar seus valores, mas estes não necessitam de defesa quando são diferentes daqueles dos outros, ou mesmo da maioria, em sua cultura (LACEY, 2010, p. 49).

Assim, mesmo que nossas práticas virtuais contemporâneas nos mova transparência da subjetividade, há também que se refletir sobre a necessidade de manter a privacidade da subjetividade, mesmo diante da tirania da informação que desinterioriza subjetividades. Neste sentido, é interessante ressaltar o esforço de Habermas e Han em promover o esclarecimento coletivo acerca de nossas práticas. Pois, de fato, parece imprescindível compreender que estamos "[...] dominados por uma ditadura do capital" (HAN, 2018, p. 15), em que nos tornamos empreendedores de nós mesmos, por meio da autogestão dos projetos de vida, independentemente da classe social a que pertencemos. Trata-se, talvez, de resistir às tiranias do upgrade.

Para que se realize qualquer nível de resistência, seja no nível micro ou macro, é necessário o recurso ao passado, ou seja, voltar nossa atenção para nossa própria experiência e para o significado de atribuímos para a nossa vida. Outra possibilidade seria reforçarmos nossa apreensão sobre os dois outros elementos antes mencionados, além da tecnologia, mas que podem funcionar como limites aos projetos livres de qualquer coerção, à produção e à autoprodução sem limites: (1) o tempo que dispomos para a nossa vida e (2) o corpo.

$\mathrm{Na}$ medida em que a temporalidade da experiência de vida e a nossa corporeidade são componentes inescapáveis da situação, da nossa relação com o mundo que nos cerca, proporcionando o retorno da compreensão de que somos, além de projetos inacabados, corpos vivos. Embora Han, por vezes, se mostre pessimista no diagnóstico da contemporaneidade, pois, para ele:

Atualmente, já não trabalhamos por causa de nossas próprias necessidades, e sim pelo capital. O capital gera as suas próprias necessidades, que erroneamente percebemos como se fossem nossas. O capital representa uma nova transcendência, uma nova forma de subjetivação. Uma vez mais, somos arremessados para fora do plano imanente da vida, na qual a vida se relaciona consigo mesma em vez de se sujeitar a um fim extrínseco (HAN, 2018, p. 16 - 17).

Pensar o plano imanente da vida é canalizar as nossas energias para recompor a trama da existência que apresenta temporalidade e corporeidade próprias. Almejar incessantemente um mundo sem materialidade (virtualmente ou por intermédio da imaginação) e que faz parte de um projeto extrínseco às nossas experiências de vida ou àquilo que podemos estabelecer livremente como projeto, é, aos poucos, provocar um sentimento subjetivo de insatisfação, de esgotamento e de angústia. Enquanto agentes, somos plenamente capazes de escolher entre projetos de vida futura e nos esforçarmos para alcançá-los e para mantêlos consistentemente durante nossas vidas.

No entanto, o sujeito do desempenho arrisca-se a perder de vista os objetivos significativos, pois investe em elementos extrínsecos, que acredita dotar a sua vida de significado, ao mesmo tempo em que expõe demasiadamente a sua subjetividade. A posse material ou a exteriorização da subjetividade podem estar sendo realizadas não por uma escolha autônoma, mas por pressões heterônomas. Cabendo, portanto, 
refletirmos sobre a nossa condição de sujeitos do desempenho.

\section{Considerações finais}

A resposta para a pergunta de se o sujeito do desempenho é apenas um projeto inacabado pode receber várias respostas. Se resgatarmos o sentido de experiência humana com associada ao corpo vital, visualizaremos em que medida a mortalidade, o corpo e a própria tecnologia servem ora vivenciarmos a nossa liberdade episódica, ora como fonte de frustração de nossa liberdade, devido à associação com o controle e com a superexposição da subjetividade.

$\mathrm{Na}$ medida em que as tecnologias, tais como a biotecnologia e a tecnologia de informação, estão cada vez mais entranhadas nos níveis micro e macro da experiência humana das sociedades industriais ou modernas, a complexidade de valores e de práticas de vida não parece permitir uma resposta única sobre se deveríamos ou não aderir inquestionavelmente às tecnologias. Porque, ademais, enquanto estrutura, a tecnociência atravessa tanto a coletividade, quanto se aproxima cada vez mais do que antes considerávamos as duas reservas de resistência: o corpo e a mente. A analítica do poder de Foucault proporciona um alento, na medida em que para todo poder mantêm-se a possibilidade de opor resistência.

$\mathrm{Na}$ medida em que as tecnologias de informação tendem a estimular a superexposição das subjetividades, cabe a possibilidade de que cada indivíduo autônomo prescreva para si mesmo o limite razoável, a partir da consideração entre a privacidade dos valores que o constituem subjetivamente e suas práticas sociais objetivas, sejam elas exercitadas no ambiente real ou virtual.

\section{Referências}

AYMORÉ, Débora \& COELHO, André. Do biopoder ao cuidado de si. PRACS: Revista Eletrônica de Humanidades do Curso de Ciências Sociais da UNIFAP, Macapá, v. 12, n. 1, 2019.

BAUMAN, Zygmund (2000). Modernidade líquida. Tradução Plínio Dentzien. Rio de Janeiro: Zahar, 2001.

BENTHAM, Jeremy (1791). O Panóptico ou a casa de inspeção. Tradução Tomaz Tadeu. 3 ed. Belo Horizonte: Autêntica, 2019, p. 15 - 85.

BRESSER-PEREIRA, Luiz Carlos. As duas fases da história e as fases do capitalismo. Textos para discussão, 278, São Paulo, 2011. Disponível em: <https://bibliotecadigital.fgv.br/dspace/bits tream/handle/10438/8081/TD\%20278\%20-\%20Luiz\%20Carlos\%20Bresser\%20Pereira.pdf>.

. Capitalismo financeiro-rentista. Estudos Avançados, v. 32, n. 92, São Paulo, 2011, 17-29.

COMPARATO, Fábio Konder. Capitalismo: civilização e poder. Estudos Avançados, v. 25, n. 72, São Paulo, 2011, p. 251 - 276.

DIAS, Ana Cristina Garcia \& TEIXEIRA, Marco Antônio Pereira Teixeira. Auto-revelação como na Internet: um estudo de caso com estudantes universitários. Aletheia, v. 27, n. 1, Rio Grande do Sul, 2008, p. 23 - 35.

FOUCAULT, Michel (1976). História da sexualidade: a vontade de saber. Tradução Maria Thereza da Costa Albuquerque; J. A. Guilhon Albuquerque. Rio de Janeiro, São Paulo: Paz e Terra, 2014.

HABERMAS, Jürgen (2001). O futuro da natureza humana: a caminho de uma eugenia liberal? Tradução Karina Janini. São Paulo: Martins Fontes, 2004. 
HAN, Byung-Chul (2014). Psicopolítica - o neoliberalismo e as novas técnicas de poder. Tradução Maurício Liesen. Belo Horizonte: Editora Âyiné, 2018.

LACEY, Hugh. Valores e atividade científica. 2 ed. São Paulo: Associação Filosófica ScientiaeStudia/ Editora 34, 2008.

LE BRETON, David (1990). Antropologia do corpo e modernidade. Tradução Fábio dos Santos Creder Lopes. 3 ed. Petrópolis, RJ: Vozes, 2013.

SIBILIA, Paola. O homem pós-orgânico: a alquimia dos corpos e das almas à luz das tecnologias digitais. 2 ed. Rio de Janeiro: Contraponto, 2015.

SILVA, Leonardo Werner (2001). Internet foi criada em 1969 com o nome de "Arpanet" nos EUA. Folha de São Paulo. Disponível em: <https://www1.folha.uol.com.br/folha/cotidiano/ult95u3480 9.shtml>.

Artigo recebido em: 16 de dezembro de 2019

Artigo aceito em: 26 de dezembro de 2019 